\title{
Navigating research currents - emerging Pasifika researcher?
}

\author{
Vaiolesi Passells
}

First generation Aotearoa New Zealand born Niue/Palagi, Vaiolesi is the daughter of Manogi Fifisi Heatu Makaea from the village of Mutulau in Niue and Frederick Passells from Portsmouth, England. She is the blessed mother of four, and grateful Nanny Vai to five mokopuna. Currently a lecturer at the School of Counselling, Human Services and Social Work (CHSSWK), Faculty of Education, University of Auckland.

\section{Abstract}

The title of this work speaks to my experience as an emerging researcher in a tertiary environment. Seventeen years ago, during my introduction to research as a required topic of study, I recall making the comment '... up until now I have measured things with a ruler'. More recently I have come to understand the research processes as premised on the economic imperatives of an information age. Implicit in this is the acquisition of knowledge based on intellectual property, where research for the sake of research vies with sites seeking to create purposeful research as conduits to informing policy and improved circumstances. In truth, the drive and thrust of Performance Based Research Fund (PBRF) imperatives in my place of work has changed the original content of my work in bridging education and social work training to where the teaching component is no longer the primary focus. Certainly external factors have played a contributing role in structural and systems changes of the institution (for example, amalgamation with a leading university), however the PBRF environment across campuses is now the norm. Research outputs increasingly help to fund tertiary institutions. This article draws attention to some reflections of the writer with regard to notions of an emerging Pasifika researcher.

One of the thrusts of research that finds favour with this learner is the impetus over recent years for Maori and Pasifika (diaspora) groups to become more pro-active about areas of policy development affecting us - health, education and schooling, employment, identity and indigeneity, economic global imperatives, local issues and so forth.

'Quality' research toward improving outcomes (of service delivery) is the incentive for purposeful research that is to influence and be understood and acknowledged, by politicians and policy makers. For an emerging researcher, the tenets of research rules and regulations are for the most part western and the literature informing the how, when and where of research is extensive and well documented. The implications of this, however, hasveresulted in unfavourable outcomes for Pasifika peoples, that is also well documented. For this circumstance to improve it is argued that Pasifika development and policy initiatives that affect Pasifika must be influenced by Pasifika thought (Sanga, 2004, p. 14). Included in the obligation and responsibility of research, is the 'credibility' of the Pasifika researcher to research things Pacific. That is to say, Pasifika research must be believed by those with the 
power to implement findings and recommendations, while at the same time maintaining Pasifika-specific integrity - trusted by Pasifika communities. Therefore an intrinsic part of research methodology is the clarification of whether the research is by an 'insider', an 'outsider' or, in some instances, a combination of both.

\section{Pacific research is political}

Historically, research on and of things Pasifika has been just that, and, according to Timote (2006), with comparatively little social or economic improvement in the health and education of Pasifika populations. Smith (1992, in Timote 2006), posits that such research has been conducted in terms of covert non-Maori/ Pacific ideological frameworks. In the past, an analysis of research knowledge as 'power' and therefore to be guarded (gate-keeping) allowed for those with 'latch keys' to sustain control. Contemporary notions of currents of knowledge as 'power' are navigated via global technologies that allow access to knowledge across cultural and state boundaries, more rapidly than has been possible before. In this way knowledge is more likely to become shared. Power shared in this context, however, is not a necessary outcome in these circumstances. Among various Pasifika researchers and writers, Nabobo-Baba (2004, p. 22) argues that the knowing of other peoples remains an ally of economic and political control by the dominant ideology.

The conceptual framework in Figure one reflects an ecological mixed metaphor of navigating research currents under bridge spans. Research currents at a personal level resonates with Hau'ofa's (1993, p. 9) grassroots places of understanding, in tandem with historic connections forged centuries prior to the migrations of Europeans:

... in the days when boundaries were not imaginary lines in the ocean, but rather points of entry that were constantly negotiated and even contested ... the sea was open entry to anyone who could navigate their way through ...

\section{Figure one.}

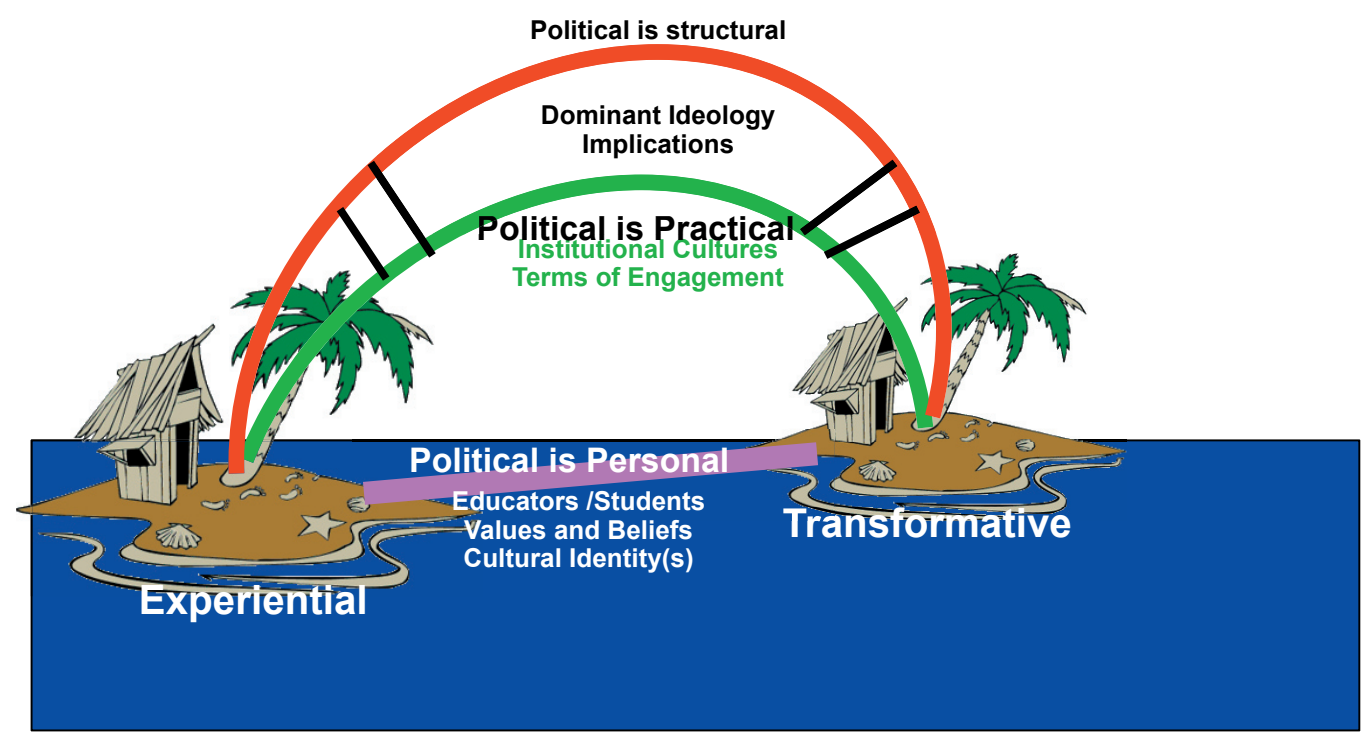


The tensions of high and low tides, rip tides, and the ebb and flow of lapping waves highlights for the author research currents to be navigated, as '... knowledge systems of indigenous peoples receive greater global, regional, national and local attention' (Sanga, 2004 , p. 41). The imperative to achieve research outputs is defined at all levels of the political span. Historically it may be proffered that notions of conducting research in terms of what works/what doesn't, what is of value/what isn't, and why, could be premised on the ancient truths of myths and legends that have stood reliability/validity tests of time for eons. Is it not from such tenets that the values and beliefs underpinning cultural understandings and world views are seeded and realise fruition? Nevertheless, the impetus to conduct research in contemporary times is carried out in climes of meritocratic values where talent, intelligence and job security is measured by the depth and breadth of research portfolios.

Smith (in Nabobo-Baba, 2004) goes so far as to state that research is a conduit through which imperialism and colonialism continues to be realised. In quoting Foucault's warning about the relations of power as more about 'how it happens' than who exercises it, Nabo-Baba (2004, p. 21) highlights that 'it happens' through the dominating of 'spaces to create knowledge'. In other words knowledge is power, and power to control rather than to share remains the tenet of competitive economies. The 'how' is evident when it is underpinned by dominant ideologies whose business it is to project and protect ways of knowing that maintain positions of privilege. To those ends, research on and of Pasifika peoples remains contested.

High tides of grassroots knowledge and reciprocal relational methods must navigate rip tides of historic dominance as well as low tides of potentially inhibiting inter-generational experiences of being the subjects of research outputs projecting deficit assumptions. The $e b b$ and flow of waves lapping at the feet of bridges built to span - institutional cultures and practical terms of engagement, as well as the implications of structural ideology - infers the necessity of consistent navigation skills and never-flagging strength required of Pasifika research integrity.

An approach could be to research the researchers and the contexts from which their respective research agendas are derived. It may expose deficit theoretical approaches (Baba, 2004, p. 96) that do not position as paramount Pasifika grassroots notions and understandings of when, where and how in tandem with notions of reciprocity (giving back to the researched). It may also devise an imperative to self-critique, lest we harm ourselves by disregarding and oppressing our knowledges and epistemologies (Daes, 2000, in Nabobo-Baba, 2004, p. 20).

Nabobo-Baba also addresses the latest bureaucracy of PBRF imperatives, among others, as hardly known outside university and wananga (tertiary learning) circle; and notes that the impact of the funding scheme is yet to be realised. Despite the progressive inclusion of comprehensive guidelines for Pasifika research, there remains little recognition of Pasifika research, the use of which is often at the discretion of chairpersons of relevant subject panels. The drive within academies to attain knowledge may at times benefit researchers and academies more than realising benefits to the researched. It is these circumstances that continue to require mindfulness and due diligence. 


\section{Pasifika research is specific}

The focus of feminist research may be directed at issues to do with women (and children) in contexts of gender bias of patriarchal systems and political structures. Similarly the locus of concern for radical research may seek ways to change the root causes of social injustice. In this way, Pasifika research seeks to know and to serve things Pasifika.

It could be a valid observation to note that the terms of reference for research engagement remain in the ebbing tides of post-colonial notions of 'the right way to do proper research'. However the hitherto privileging discourse and systems of methods and principles used in research (methodology) to favourably position some sites for knowledge creation while marginalising and silencing others does not continue to go unchallenged (Nabobo-Baba, 2004, p. 22).

Western philosophies, epistemologies and ways of knowing themselves, let alone 'others', is subjective, according to Hume (in Davidson and Tolich, 1999, p. 36), despite assertions of scientific objectivity and the importance of valid measurement that is required to inform of truths (Timote, 2006). Smith (in Nabobo-Baba, 2004, p. 21), on relations of power, asserts that '... the deriving of power in many instances has happened through dominating the spaces to create knowledge, and the adjudicating of which knowledges and ways of knowing are valid and therefore legitimate'.

It is these spaces that have become points of entry to be negotiated and even contested (Hau'ofa, 1993) in Pasifika research. For example Sanga (2004) proposes the development of Pasifika research within its own philosophical orientation based on sociological assumptions.

In 2002 the Ministry of Education commissioned a report to draw up Pasifika Education Research Guidelines. The Auckland-based Pacific Business Trust also commissioned a report calling for advice on how research on and with Pasifika communities could be made credible to Pasifika communities, as well as ensuring that the research that is undertaken is reciprocal (Sanga, 2004, p. 42). Since then numerous agencies have produced similar documents, all of which use cultural imperatives for recognising Pasifika research. This suggests to me that there are many methods and approaches to undertaking Pacific research in the contexts of similarities and commonalities, yet allowing for diversity, among Pasifika - the specifics of which may be drawn out and expanded on respectively.

More recently, Maori and Pacific writers and researchers articulate variously the need to: negotiate research networks (Smith, 2004, p. 8); for leadership to continue to be politically 'savvy' (Baba, 2004, p. 103); be familiar with the general theory of nature, mind and society (ta-va) transformation (Mahina, 2002, pp. 5-9); facilitate Pasifika epistemologies (Timote, 2006, p. 22) to name a few examples. Furthermore Sanga (2004, p. 42) debates strategies for conceptualising indigenous Pacific research ' $\ldots$ in its search for credibility'. To that, Anae (class communication, 2009) draws attention to Pacific indigenous philosophical Teu le va methodology - and which focuses on the centrality of reciprocal relationships - to complement the Ministry's 2002 Pasifika Education Research Guidelines. 
It appears that there are strategic developments leading away from the dangers of assuming that all Western, Eastern and Pasifika knowledge(s) have the same origins and could therefore, by implication, be subject to the same research tools used to construct new knowledge (Timote, 2006, p. 22). There is a plethora of Pasifika-specific resources in Pacific communities, and the challenge now is marshalling these resources towards Pacific research that is research for, by and with Pacific methodologies to underpin Pacific methods and approaches for the sake of positive and reciprocal outcomes.

\section{Pacific research is 'insider/outsider’ discourse}

For reasons previously discussed it is vital for transparency to be considered when undertaking Pacific research, about whether one is a Pasifika researcher or a researcher who is Pasifika. In her article, Anae (1996) uses a poem by Thaman to articulate the, 'it hurts' potential to be experienced either way - objectifying penchant of Western research initiatives (outsider) and the danger of hidden value judgments and assumptions of 'insider' research (Patai, 1991, in Williams, 2004, p. 166).

The power dynamics of imperialism and the Eurocentric administrations of colonialism by definition serve to maintain the 'status quo' inasmuch as gate keepers of knowledge serve the interests of Western paradigms. That is to say, in contrast to Pacific collective obligations and responsibilities (Taufe'ulungaki, in Williams, 2004, p. 160), majority democracy is served instead - based on assumptions of individual rights and freedoms as the basic polity of society to serve market-driven economics and ideology.

'Insider' research tenets therefore are varied and complex, and embrace more than being born into an ethnicity. While some scholars insist on language-specific imperatives to determine valid Pacific credibility, Anae argues that emotional ties are significant factors which complement the status of 'insider'. However it is to be defined by respective Pacific researchers, defined it must be, and kept to the forefront of researcher mindfulness lest we forget '... it is not possible to write about the oppressed without becoming one of the oppressors' (Patai, 1991, in Williams, 2004, p. 166). In other words, it is not enough to claim 'insider' status when in truth we are accorded 'outsider' status by our very actions as privileged recipients of knowledge and the power dynamics embedded in researching processes.

Among developing epistemologies of research methodology and methods, in Pacific research, notions of reciprocity and subjectivity (qualitative) have a vital place in terms of credibility, validity, ethicality, reliability and so forth. How Pasifika researchers reconcile the juxtaposition of 'insider / outsider' affords measures of accountability and research credibility from the stance of the researcher and the researched.

\section{Conclusion}

Pasifika research is underpinned by obligations and responsibilities that are to do with things Pasifika in terms of transformative health, education, housing, paid employment, aspirations and optimal 'life opportunities'. Implicit in Pasifika ethnicities and cultures are shared similarities and commonalities with regard to the wellbeing of respective collectives. To that, an aqualogical paradigm (Figure one) may also allude to notions of shared memories at personal, practical and structural spaces and depths. Yet another dimension in that com- 
plexity are Pacific research epistemologies and philosophies which are fast developing the tools with which Pasifika researchers, 'insider' and 'outsider' alike, may become versed in and with whatever is necessary to navigate reciprocal Pasifika-specific research currents.

\section{References}

To the writers, editors, contributors and the Centre for Pacific Studies, The University of Auckland for their collective wisdoms in the book Researching Pacific and Indigenous Peoples: Issues and perspectives - fakaaue lahi.

Anae, M. S. (1996). Inside out: methodological issues on being a 'native' researcher. Pacific Health Dialog, 5(2).

Baba, T. (2004). Pacific and indigenous research: beyond bondage and patronage. In T. Baba, O. Mahina, N. Williams, \& U. Nabobo-Baba (Eds.). Researching the Pacific and indigenous peoples: Issues and perspectives. University of Auckland: Centre for Pacific Studies.

Davidson, C., \& Tolich, M. (1999). Competing traditions. In C. Davidson, \& M. Tolich (Eds.). Social science research in New Zealand: many patterns to understanding (2nd ed.)

Hau' ofa, E. (1993). A new Oceana: Rediscovering our sea of islands. In E. Waddell, \& E. Hau' ofa (Eds.). School of Social and Economic Development: The University of the South Pacific in Association with Beake House.

Hau'ofa. E. (1993). Our sea of islands. Paper to the lectures delivered in the University of Hawaii at Hilo and the east west cebtre, Honolulu, March/April, 1993. Cited by Nabobo-Baba, in In T. Baba, O. Mahina, N. Williams, \& U. Nabobo-Baba (Eds.). Researching the Pacific and indigenous peoples: Issues and perspectives. University of Auckland: Centre for Pacific Studies.

Mahina, O. (2002). Tufunga lalava: the Tongan art of lineal and spatial intersection. In S. Rees, (Ed.). Filipe Tohi: Genealogy of lines: Hohoko e tohitohi. New Plymouth: Govett-Brewster Art Gallery, pp. 5-9.

Nabobo-Baba, U. (2004). Research and Pacific Indigenous Peoples: Silenced pasts and challenged futures. In T. Williams, N. (2004). On the inside: narratives from the frontline. In T. Baba, O. Mahina, N. Williams, \& U. Nabobo-Baba (Eds.). Researching the Pacific and indigenous peoples: Issues and perspectives. University of Auckland: Centre for Pacific Studies.

Sanga, K. F. (2004). Making philosophical sense of indigenous Pacific research. In T. Baba, O. Mahina, N. Williams, \& U. Nabobo-Baba (Eds.). Researching the Pacific and indigenous peoples: Issues and perspectives. University of Auckland: Centre for Pacific Studies.

Smith, L. (2004). Building research capability in the Pacific, for the Pacific and by Pacific peples. In T. Baba, O. Mahina, N. Williams, \& U. Nabobo-Baba (Eds.). Researching the Pacific and indigenous peoples: Issues and perspectives. University of Auckland: Centre for Pacific Studies.

Timote, M., V. (2006). Talanoa research methodology: a developing position on Pacific research. Waikato Journal of Education, 12.

Williams, N. (2004). On the inside: narratives from the frontline. In T, Baba, O. Mahina, N. Williams, U. NaboboBaba. (Eds.). Researching the Pacific and Indigenous Peoples: Issues and perspectives. University of Auckland: Centre for Pacific Studies. 